\title{
Fracture of Distal Third Clavicle with Posterior Displacement and Trapezius Interposition In 7 Year Old child- A Case Report
}

\author{
Barani.R, Lingaraj, Selvam.N, Syed Najimudeen, Kanagasabai.R, \\ James J Gnanadoss \\ Department Of Orthopedics - Pondicherry Institute Of Medical Sciences, Pondicherry, India.
}

\begin{abstract}
Lateral end clavicle fractures in children are relatively rare which due to the displacement are often considered for surgical management Distal third fractures with posterior displacement which entraps trapezius often requires open reduction to realign the fragment by removing the interposed soft tissue .We report an injury in a 7 years old child after fall on to outstretched hand which resulted in posteriorly displaced and rotated distal third junction clavicle fracture with trapezius interposition. Considering the age, and significant deformity, open reduction without internal fixation was done under general anaesthesia.
\end{abstract}

Keywords: lateral end clavicle, trapezius

\section{Introduction}

Clavicle is the most common long bone fracture in pediatric age group accounting for $10-15 \%$ of pediatric fractures ${ }^{1}$. Middle one third fractures constitute nearly $90 \%$ of the clavicle fractures which usually are managed conservatively with excellent clinical results. Lateral third fractures are relatively rare which due to the displacement are often considered for surgical management. Percutaneous ' $\mathrm{k}$ ' wire fixation, open reduction and stabilization with ' $\mathrm{k}$ ' wires and plates are the options considered depending on the fragment size and displacement. Distal third fractures with posterior displacement which entraps trapezius often requires open reduction to realign the fragment by removing the interposed soft tissue.

There is only a single case reported in literature of pediatric clavicle fractures where lateral third clavicle fracture has shown posterior displacement with trapezius interposition following direct impact injury ${ }^{2}$.

We report a displaced fracture which had trapezius interposition following indirect injury, i.e. Fall on to a outstretched hand which was managed by open reduction and stabilization using ethibond anchors which avoids complications and secondary procedures which follow internal fixation methods like ' $\mathrm{k}$ 'wire fixation। plate fixation.

\section{Case Details}

A 7 years old boy who was travelling in a two wheeler as a pillion rider fell onto a outstretched hand following road traffic accident. He presented with pain and swelling with deformity of right shoulder with restriction of movements. There were no other associated injuries. There were no cutaneous markers of direct impact anteriorly or posteriorly around right shoulder. There was no distal neurovascular deficit.

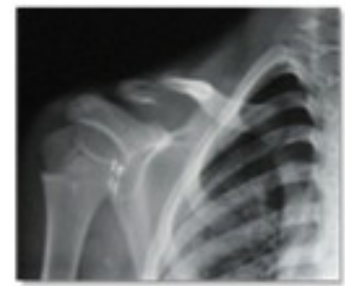

$\operatorname{Fig}(\mathbf{A})$

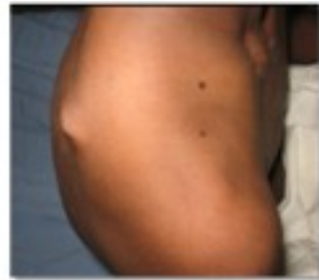

$\operatorname{Fig}(\mathbf{B})$

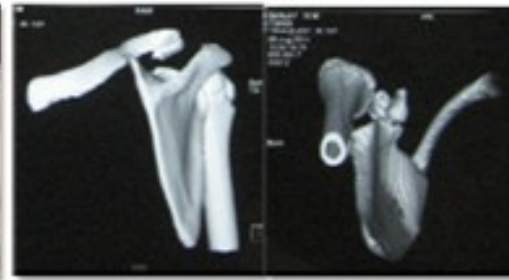

$\operatorname{Fig}(\mathbf{C})$

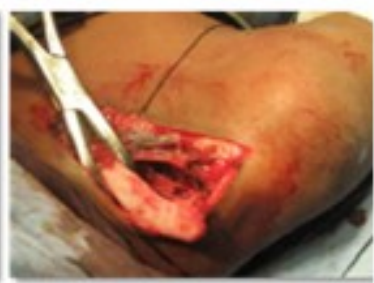

Fig(D)

Fig(A)-radiographs revealed a fracture in medial $2 / 3$ rd lateral $1 \backslash 3 \mathrm{rd}$ junction clavicle with marked posterior angulation and rotation with intact acromio clavicular joint

Fig(B)-clinical picture showing deformity without evidence of direct impact .

Fig(C)-ct scan with 3 dimensional reconstruction confirm the fracture pattern and orientation of displacement.

Fig(D)- intra -operative image showing displacement and entrapment.

\subsection{Operative Details}

Under general anaesthesia closed manipulation was attempted twice in vain, following which open reduction using approximately $6 \mathrm{~cm}$ transverse incision connecting the ends of fracture was done. Trapezius muscle was found be interposed between fracture fragments with significant stretch of subclavius. Using a towel clamp the fragment was manipulated and pulled anteriorly to achieve anatomical reduction. 
Ethibond suture material (delayed absorbable) was used to secure medial end of fracture to the lateral fragment and periosteal sleeve which was found to be intact inferiorly. Shoulder immobilizing sling was given for a duration for 3 weeks with initiation of active assisted shoulder exercises. 4 weeks post operatively there was no demonstrable tenderness at fracture site with radiological evidence of callus formation with complete restoration of range of motion. At the 12 weeks there was complete union at fracture site with excellent functional outcome (DASH score).

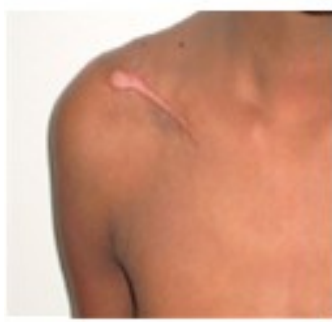

$\operatorname{Fig}(\mathbf{E})$

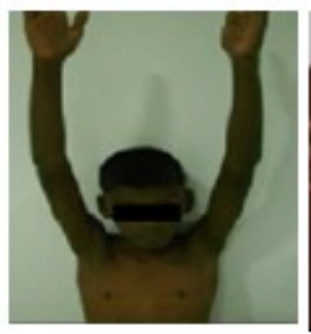

Fig(F)

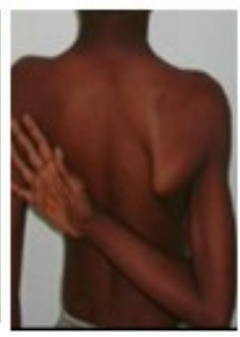

$\operatorname{Fig}(G)$

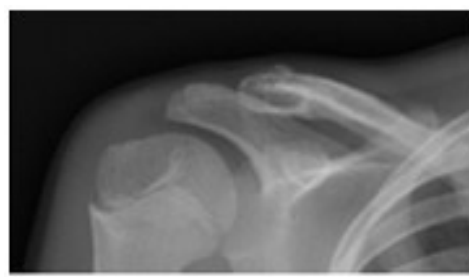

$\operatorname{Fig}(\mathbf{H})$

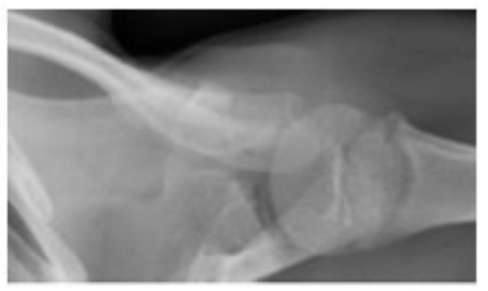

Fig(I)
Fig $(E, F, G)$ - healed surgical scar with preserved shoulder movements comparable to normal shoulder

Fig $(H, I)$ - 12weeks post operative radiographs (anteroposterior lateral) showing united fracture

\subsection{Discussion}

Lateral third clavicle fractures account for $10-20 \%$ of clavicle fractures in immature skeleton. Age of the patient and degree of displacement determine the necessity to operatively stabilize the fracture for good functional results. Complications like restriction of movements secondary to shortening, duplication of clavicle, hypertrophic callus are common in fractures which are displaced and are managed conservatively ${ }^{3}$.

Havranek et $\mathrm{al}^{3}$ report of 10 cases concluding that conservative management does not affect functional outcome irrespective of the cosmetic concerns. Nenopoulos et $\mathrm{al}^{4}$ have classified distal clavicle fractures based on the fracture pattern and displacement. They advocate surgical management in distal clavicle fractures with more than 2 cortices displacement in children above 8 years of age. Even though the healing and remodeling potential is enormous due to intact inferior periosteum, impaired functional outcome and cosmetic concerns are common in severely displaced injuries.

Displaced fractures are often due to direct injuries like collision. Clavicle fractures in pediatric age group following indirect injury are rare ${ }^{5}$. To the best of our knowledge there are no reports of indirect injuries resulting in severe posterior displacement which could result in trapezius interposition. The only other case report of Itokazu et $\mathrm{al}^{2}$ which had posterior displacement with trapezius interposition was following direct injury which was managed by open reduction and ' $\mathrm{k}$ ' wire fixation.

Considering the potential ' $\mathrm{k}$ ' wire complications like pin site infection, intra-thoracic migration ${ }^{6}$ we had used ethibond sutures to anchor the reduced fragment which had given a satisfactory radiological and functional result.

\section{Conclusion}

Distal third fractures with posterior displacement which entraps trapezius often requires open reduction to realign the fragment by removing the interposed soft tissue. Ethibond anchors give favourable results by avoiding complications and secondary procedures which follow internal fixation methods like ' $\mathrm{k}$ 'wire fixation $\backslash$ plate fixation.

\section{References}

[1]. Sarwark JF, King EC, Luhmann SJ. Proximal humerus, scapula and clavicle. In:Rockwood Jr CA, Wilkins KE, editors. Fractures in children. 6th ed., Philadelphia:Lippincott, Williams \& Wilkins; 2006. p. 724-8.

[2]. M Itokazu, M Yoshida, Y Itoh, M Hukuta, K Kikuike.Trapezius interposition of a distal third clavicular fracture in a child: A case report.Journal of Orthopaedic Surgery 2001, 9(1): 67-69

[3]. Havranek P. Injuries of distal clavicular physis in children. J Pediatr Orthop

[4]. $1989 ;(9): 213-5$. 
Fracture of Distal Third Clavicle with Posterior Displacement and Trapezius Interposition In ....

[5]. Savvas P. Nenopoulos et al. Outcome of distal clavicular fracture separations and dislocations inimmature skeleton. Injury, Int. J. Care Injured 42 (2011) 376-380

[6]. Stanley D, Trowbridge EA, Norris SH. The mechanism of clavicular fractures. A clinical and biomechanical analysis. J Bone Joint Surg [Br] 1988;70:461-464.

[7]. Hegemann S, Kleining R, Schindler HG, Holthusen H. Kirschner wire migration in the contralateral lung after osteosynthesis of a clavicular fracture. Unfall-chirurg 2005;108(11):991-3. 